\title{
Effect on Some Plant Growth Parameters of Magnesium Applications in Pepper Plants under Salt Stress
}

\author{
Neslihan Sevgin Zirek \\ Van Yuzuncu Yil University, Graduate School of Natural and Applied Sciences, Van, Turkey \\ E-mail: neslihan-sevgin@hotmail.com \\ Ozlem Uzal (Corresponding author) \\ Van Yuzuncu Yil University, Faculty of Agriculture, Department of Horticulture, Van, Turkey \\ E-mail: ozlemuzal@yyu.edu.tr
}

The research was supported by BAP (The Scientific Research Projects Coordination Unit)

(Project no. FYL-2016-5148)

\begin{abstract}
In the study of using Demre pepper seeds, morphological and biochemical effects of magnesium (Mg) applied at different doses of pepper plant under salt stress were investigated. The study was carried out in 16/8 hour light / dark photoperiod, $25{ }^{\circ} \mathrm{C}$ and $70 \%$ humid climate room in controlled conditions. In the study, root weight, stem weight, leaf weight, number of leaves, plant height and plant node spacing were measured. In addition, the salt tolerance scales of the plants were determined.

Seedlings of Demre pepper cultivar were grown in Hoagland nutrient solution and $100 \mathrm{mM} \mathrm{NaCl}$ was applied to the plants to apply salt stress. In addition to salt application to the plants, $\mathrm{Mg}$ doses $\mathrm{Mg} 1=49,28$ ppm, $\mathrm{Mg} 2=24,64$ ppm, Mg3 = 73,92 ppm, Mg4 = 98,56 ppm, Mg5 = 123,20 ppm)were applied in different doses and the growth of the plants were compared. On the 20th day of the salt application, some growth parameters of the plants were examined and the salt resistance scales of these applications were formed according to the scale 1-5. Increasing doses of $\mathrm{Mg}$ together with salt application resulted in small increases in root, stem and leaf weight of pepper plants. Among the salt applications, the highest root, stem and leaf weight were taken from the fourth dose of $\mathrm{Mg}$. The same conditions were observed in terms of the number of leaves, plant height and internodes. When the scale values are examined, it is seen that the least affected plants are in $\mathrm{Mg} 4+$ Salt application. It is followed by $\mathrm{Mg} 3+$ Salt, $\mathrm{Mg} 5+\mathrm{Salt}$ and $\mathrm{Mg}$ $2+$ Salt applications respectively. The most morphologically damaged application is $\mathrm{Mg} 1+$ Salt. It can be said that increasing doses of $\mathrm{Mg}$ had a positive effect on the development of plants under salt stress in this study which was conducted with the assumption that salt stress could reduce the negative effect on plant growth.
\end{abstract}

Keywords: Salt stress, Magnesium, $\mathrm{NaCl}$, Pepper (Capsicum annum L.)

DOI: $10.7176 /$ JSTR/5-10-05

\section{Tuz Stresi Altındaki Biber Bitkilerinde Magnezyum Uygulamalarının Bazı Bitki Büyüme Parametrelerine Etkisi}

\author{
Özet \\ Demre biber çeşidinin kullanıldığı çalışmada tuz stresi altındaki biber bitkisine farklı dozlarda uygulanan \\ magnezyumun $(\mathrm{Mg})$ morfolojik ve biyokimyasal etkileri araştırılmıştır. Çalışma kontrollü şartlardaki \\ $16 / 8$ saatlik aydınlık/ karanlık fotoperiyotta, $25^{\circ} \mathrm{C}$ 'de ve $\% 70$ nemli iklim odasında yürütülmüştür. \\ Çalışmada kök ağırlığı, gövde ağırlı̆̆ı, yaprak ağırlığı, yaprak sayısı, bitki boyu ve bitki boğum arası
}


mesafeleri ölçülmüştür. Ayrıca bitkilerin tuza dayanım skalaları belirlenmiştir.

Demre sivri biber çeşidine ait fideler Hoagland besin çözeltisi içinde yetiştirilmiş ve bu bitkilere tuz stresi uygulamak için $100 \mathrm{mM} \mathrm{NaCl}$ uygulanmıştır. Bitkilere tuz uygulamasının yanında değişik dozlarda $(\mathrm{Mg}$ 1=49,28 ppm, Mg 2 =24,64 ppm, Mg3 = 73,92 ppm, Mg4 = 98,56 ppm, Mg5 = 123,20 ppm) Mg uygulamaları yapılmış ve bitkilerin gelişme ve büyüme yönünden karşılaştırması yapılmıştır. Tuz uygulamasının 20. gününde bitkilerin bazı gelişme parametrelerine bakılmış ve bu uygulamaların tuza dayanım skalaları 1-5 skalasına göre oluşturulmuştur. Tuz uygulaması ile birlikte artan dozlarda $\mathrm{Mg}$ uygulanan biber bitkilerinin büyüme ve gelişme parametrelerinden kök, gövde ve yaprak ağırlığ bakımından ufak da olsa artışlar görülmüştür. Tuz uygulamaları içinden en yüksek kök, gövde ve yaprak ağırlığı Mg' un dördüncü dozundan alınmıştır. Aynı durumlar yaprak sayısı, bitki boyu ve boğum arası bakımından da gözlemlenmiştir. Skala değerlerine bakıldığında tuzdan en az etkilenen bitkilerin $\mathrm{Mg}$ 4+Tuz uygulamasında olduğu görülmektedir. Bunu sirasıyla Mg 3+Tuz, Mg 5+ Tuz ve Mg 2+Tuz uygulamaları izlemektedir. Morfolojik olarak en fazla zararlanma gören uygulama ise $\mathrm{Mg} 1+\mathrm{Tuz}$ uygulamasıdır. Tuz stresinin bitki gelişimi üzerine olumsuz etkisini azaltabileceği öngörüsüyle yapılan bu çalışmada tuz stresi altındaki bitkilerin gelişimi üzerine $\mathrm{Mg}^{\prime}$ nin artan dozlarının olumlu etkisinin olduğu söylenebilir.

\section{Anahtar kelimeler: Tuz stresi, Magnezyum, NaCl, Biber (Capsicum annum L.)}

\section{Giriş}

Bitkilerde birçok metabolik olayı olumsuz yönde etkileyen ve özellikle kültür bitkilerinde ürün kalitesi ve verimi düşüren önemli abiyotik faktörlerden biri olan tuz stresi, gerek açıkta ve gerekse örtü altı yetiştiricilikte önemli payı olan biber bitkisini olumsuz etkilemektedir. Tuzluluk örtü altı yetiştiricilik alanlarında, açıkta yetiştiricilikten çok daha etkin olmaktadır. Topraksız sistemlerde dahi düşük kaliteli su kullanımı tuzluluk açısından sorunlara neden olmaktadır (Oztekin, 2011). Tuzluluk genel olarak; bitkinin yaprak sayısı ve alanında azalma; bitki boyutunun küçülmesi, dokular ve organların farklılaşması ve büyümesini baskılaması, kök ve gövde ağırlığının dengelenememesi sonucunda daha çelimsiz kök oluşmasıyla kendisini göstererek büyümede yavaşlamaya sebep olur. Aynı zamanda tuzluluk, bitki yaş ve kuru ağırlığında meydana gelen azalmalar, klorofil içeriğinde azalmalar, meyve kalitesinde düşüş ve buna bağlı olarak verimde oluşacak aksaklıklarla da etkisini göstermektedir (Asraf, 2004; Yu ve ark.., 2012). Bitkilerde tuz stresi büyümenin azalmasına, fotosentez hızının yavaşlamasına, reaktif oksijen türlerinin artmasına, su potansiyelinin azalmasına, iyon dengesizliğine ve stomaların kapanmasına yol açar (Taiz ve Zeiger, 2002; Bartels ve Sunkar, 2005; Mahajan ve ark., 2008).

$\mathrm{Bu}$ olumsuz şartlardan dolayı ürün ve kalite kayıpları da ciddi boyutlara ulaşabilmektedir. Ancak bu olumsuzlukları ortadan kaldırmanın en önemli ve en kesin yolu da tuzluluğa toleranslı bitki tür ve çeşitlerini geliştirmek ve tuzluluğun olumsuz etkilerini giderici uygulamalar yapmaktır. Tuz stresi altındaki biber bitkisine magnezyumun $(\mathrm{Mg})$ morfolojik ve biyokimyasal etkileri araştırılan bu çalışmada, tuz uygulaması yanında bitkilere farklı dozlarda $\mathrm{Mg}$ 'lu bileşikler uygulanarak, uygulamanın tuza dayanımını nasıl etkilediği belirlenmeye çalışılmıştır.

\section{Materyal ve Yöntem}

Bu çalışma, Van Yüzüncü Yıl Üniversitesi Ziraat Fakültesi Bahçe Bitkileri Bölümü Fizyoloji Laboratuvarı'nda normal atmosferin sağlandığı split klimalı iklim odasında ve su kültüründe yürütülmüştür. Çalışmada Demre biber çeşitleri kullanılmıştır.

$\mathrm{Bu}$ amaçla, biber tohumları, pomza ve torf doldurulmuş alt yüzeyi delinen plastik çimlendirme kaplarına ekilerek çeşme suyu ile sulanmıştır. Çimlendirme kapları, $25 \pm 1^{\circ} \mathrm{C}$ sıcaklık \% 70 neme sahip iklim odasına yerleştirilerek, üzerleri nemli gazete kâğıdıyla örtülüp kaplar ortam kurumayacak şekilde azar azar çeşme suyu ile sulanmaya devam edilmiştir. Çimlendirme kapları düzenli olarak kontrol edilmiş çıkış gerçekleştiğinde bu örtüler kaldırılmıştır. Kotiledon yaprakları yatay duruma gelen ve ilk gerçek yaprakları görülmeye başlayan fidelerde sulama Çizelge 1'de içeriği gösterilen Hoagland besin çözeltisiyle (Hoagland ve Arnon, 1938) yapılmaya başlanmıştır. Bu ortamda 2 gerçek yaprakları oluşan fideler, içinde besin çözeltisi doldurulmuş $25 \times 25 \times 18 \mathrm{~cm}$ boyutlarındaki plastik küvetler üzerine her fide için delikler açılmış plastik tablalara biber fideleri küçük sünger parçaları ile sarılmak suretiyle yerleştirilerek su kültürüne alınmıştır. Havalandırma işlemi, akvaryum pompası yardımla yapılmıştır. 
Çizelge 1. Kullanılan besin solüsyonu içerikleri (ppm)

\begin{tabular}{|l|c|c|c|c|c|c|}
\hline Elementler & $\begin{array}{c}\text { Uyg. 1 } \\
\text { Kontrol }\end{array}$ & $\begin{array}{c}\text { Uyg.2 } \\
\text { Mg1+Tuz }\end{array}$ & $\begin{array}{c}\text { Uyg.3 } \\
\text { Mg2+Tuz }\end{array}$ & $\begin{array}{c}\text { Uyg.4 } \\
\text { Mg3+Tuz }\end{array}$ & $\begin{array}{c}\text { Uyg.5 } \\
\text { Mg4+Tuz }\end{array}$ & $\begin{array}{c}\text { Uyg.6 } \\
\text { Mg5 +Tuz }\end{array}$ \\
\hline Azot (N) & 186 & 186 & 186 & 186 & 186 & 186 \\
\hline Fosfor (P) & 31 & 31 & 31 & 31 & 31 & 31 \\
\hline Potayum (K) & 135 & 135 & 135 & 135 & 135 & 135 \\
\hline Magnezyum (Mg) & 49.28 & 24.64 & 49.28 & 73.92 & 98.56 & 123.20 \\
\hline Kalsiyum (Ca) & 217 & 217 & 217 & 217 & 217 & 217 \\
\hline Kükürt (S) & 66 & 66 & 66 & 66 & 66 & 66 \\
\hline Demir (Fe) & 3.3 & 3.3 & 3.3 & 3.3 & 3.3 & 3.3 \\
\hline Mangan (Mn) & 0.031 & 0.031 & 0.031 & 0.031 & 0.031 & 0.031 \\
\hline Bor (B) & 0.205 & 0.205 & 0.205 & 0.205 & 0.205 & 0.205 \\
\hline Bakır (Cu) & 0.015 & 0.015 & 0.015 & 0.015 & 0.015 & 0.015 \\
\hline Çinko (Zn) & 0.023 & 0.023 & 0.023 & 0.023 & 0.023 & 0.023 \\
\hline
\end{tabular}

Fideler iki hafta süreyle su kültüründe büyütülerek 4-5 gerçek yaprağa sahip olan fidelere tuz uygulamalarına başlanmıştır. Tuz uygulanacak fideler için besin çözeltisine (1/2 Hoagland) $100 \mathrm{mM}$ tuz konsantrasyonunu sağlayacak $\mathrm{NaCl}$ ilave edilmiştir. Her hafta yinelenen çözeltilerin tazelenmesi aşamasında, tuz uygulamalarının aynı konsantrasyonda devamı sağlanmıştır. Biber fidelerine tuzla birlikte 5 farklı dozda (Mg 1=49,28 ppm, Mg 2 =24,64 ppm, Mg3 = 73,92 ppm, Mg4 = 98,56 ppm, Mg5 $=123,20 \mathrm{ppm}) \mathrm{MgSO}_{4}$ ilave edilmiștir. Uygulamanın 20. gününde alınan bitki örneklerinde temel bazı büyüme parametreleri yaprak sayısı (adet), yaprak ağırlığı(g), kök ağırlığı (g), gövde ağırlı̆ı 1 (g), bitki boyu $(\mathrm{cm})$ ve boğum araları mesafe $(\mathrm{cm})$, ölçümleri yapılmış ve tuza dayanım skalası oluşturulmuştur.

\subsection{Temel bazı büyüme parametrelerinin belirlenmesi}

Kök ağırlığı, yaprak ağırlı̆̆ ve gövde ağırlı̆̆ üç tekerrürlü olarak 1/10.000 lik hassas dijital terazi ile tartılmıştır. Kök uzunluğu, bitki boyu ve boğum arası mesafe cetvel ile cm olarak ölçülmüştür. Yaprak sayısı adet olarak belirtilmiştir.

\subsection{1-5 Skalast ile değerlendirme}

Bitkilerde morfolojik olarak ortaya çıkan zararlanmanın derecesini ortaya koyabilmek amacıyla bir skala oluşturulmuştur. Tuz stresi denemesinde zararlanma derecesine göre biber bitkilerine aşağıda belirtilen semptomlar bazında 1'den 5'e kadar puan verilmiştir (Üzal, 2009).

1:Bitkilerin tuz stresinden hiç etkilenmemesi (kontrol bitkileri)

2:Yapraklarda lokal sararma ve kıvrılma

3:Yapraklarda sararma ve $\% 25$ oranında nekrotik lekelenmeler

4:Yapraklarda \% 50-75 oranında nekrotik leke göstermesi ve ölümlerin görülmesi

5:Yapraklarda \% 75-100 oranında şiddetli nekrozlar ve bitkinin tamamen ölmesi

2.3. Değerlendirmelerin yapılmast

Deneme tesadüf parselleri deneme desenine göre 3 tekerrürlü ve her tekerrürde 15 bitki olacak şekilde kurulmuştur. İstatistiksel analizler SAS Institue (1985) paket programı kullanılarak yapılmıştır.

\section{Bulgular}

\subsection{Bitki gelişimiyle ilgili özellikler}

$\mathrm{NaCl}$ stresine tabi tutulan biber bitkileri 20. Gün sonunda bitkilerin kök ağırlığı, gövde ağırllğı, yaprak ağırlığı, yaprak sayısı, bitki boyu ve boğum arası mesafeleri ölçülmüş ve elde edilen değerler Çizelge 2 'de verilmiştir.

20 günlük tuz stresi sonucunda kontrol grubuna göre diğer tüm tuz uygulamalarının kök ağırlıklarında (g) istatistiksel olarak önemli düşüşlerin olduğu görülmektedir. Tuz uygulaması yapılmış bitkiler içinde kök ağırlığı bakımından en yüksek değeri Mg 2+Tuz ve Mg 3 +Tuz uygulamalarında belirlenmiştir. Kök ağırlığı açısından en düşük değerler ise $\mathrm{Mg} 1+\mathrm{Tuz}$ ve $\mathrm{Mg} 4+\mathrm{Tuz}$ uygulamalarında ölçülmüştür. Gövde ağırlığ bakımdan en yüksekdeğerler kontrol grubundaki $(3.65 \mathrm{~cm})$ itkilerden en düşük değer ise $\mathrm{Mg}$ $5+\mathrm{Tuz}(2.28 \mathrm{~cm})$ uygulaması yapılmış bitkilerden elde edilmiştir. Mg 1+Tuz, Mg 2+Tuz,Mg 3+Tuz ve Mg 4+Tuz uygulamaları ise istatistiksel olarak aynı önem grubu içerisinde kalmıştır. Yaprak ağırlığında en 
yüksek değer kontrol grubu bitkilerinde $(10.5633 \mathrm{~g})$ belirlenmiş olup; $\mathrm{Mg}+$ Tuz uygulamalarının hepsi aynı istatistiksel grupta yer almıştır. Kontrol grubuna en yakın değerler Mg3+ Tuz ve Mg4 + Tuz uygulamalarından, en düşük değer ise $\mathrm{Mg} \mathrm{1+Tuz}$ uygulamasından elde edilmiştir.Yaprak sayısına bakıldığında en yüksek değer kontrol grubundan elde edilirken $\mathrm{Mg}+\mathrm{Tuz}$ uygulamalarının tümü aynı istatistiksel grupta yer almıştır. Mg+Tuz uygulamaları içinde kontrole (12.66 adet) en yakın değer Mg 4+Tuz (10.00 adet) uygulamasıdır. En düşük ise yine Mg 1+Tuz (8.56 adet) uygulamasından elde edilmiştir. Bitki boyu bakımında yapılan uygulamalar arasında istatistiki olarak fark yoktur. Boğum arası mesafeye bakıldığında ise Mg 1+ Tuz uygulamalarının kontrolle aynı istatistiksel grupta yer aldığı, $\mathrm{Mg}$ $2+$ Tuz, Mg 3+ Tuz, Mg 4+ Tuz ve Mg 5+ Tuz uygulamalarının ise aynı istatistiksel grupta yer aldığ 1 görülmektedir. Bu uygulamaların boğum arası mesafeyi önemli ölçüde arttırdığı dikkati çekmektedir. Tuz uygulamaları arasından en yüksek boğum arası mesafe değeri $\mathrm{Mg} 2+\mathrm{Tuz}(5.16 \mathrm{~cm})$, en düşük değer ise $\mathrm{Mg} \mathrm{1+Tuz} \mathrm{(2.66} \mathrm{cm)} \mathrm{uygulamasından} \mathrm{elde} \mathrm{edilmiştir} \mathrm{(Çizelge} \mathrm{2.).}$

Çizelge 2. Uygulamalardan sonra alınan örneklerde bazı büyüme ve gelişme parametreleri

\begin{tabular}{|c|c|c|c|c|c|c|}
\hline UYGULAMA & $\begin{array}{c}\text { Kök } \\
\text { Ağırllğ́1 } \\
\text { (g) }\end{array}$ & $\begin{array}{l}\text { Gövde } \\
\text { Ağırlığ } 1 \\
\text { (g) }\end{array}$ & $\begin{array}{c}\text { Yaprak } \\
\text { Ağırlığ } \\
\text { (g) }\end{array}$ & $\begin{array}{l}\text { Yaprak } \\
\text { Sayıs1 } \\
\text { (adet) }\end{array}$ & $\begin{array}{l}\text { Bitki Boyu } \\
\quad(\mathrm{mm})\end{array}$ & $\begin{array}{c}\text { Boğum } \\
\text { aras1 } \\
\text { mesafe } \\
(\mathrm{cm})\end{array}$ \\
\hline Kontrol & $2.930 \mathrm{~A}$ & $3.657 \mathrm{~A}$ & $10.563 \mathrm{~A}$ & $12.667 \mathrm{~A}$ & 18.667 & $2.667 \mathrm{~B}$ \\
\hline Mg 1+Tuz & $1.837 \mathrm{~B}$ & $2.480 \mathrm{AB}$ & $5.107 \mathrm{~B}$ & $8.567 \mathrm{~B}$ & 16.933 & $2.667 \mathrm{~B}$ \\
\hline Mg 2+Tuz & $1.887 \mathrm{~B}$ & $2.513 \mathrm{AB}$ & $5.143 \mathrm{~B}$ & $8.667 \mathrm{~B}$ & 17.133 & $5.167 \mathrm{~A}$ \\
\hline Mg 3+Tuz & $1.887 \mathrm{~B}$ & $2.430 \mathrm{AB}$ & $5.820 \mathrm{~B}$ & $9.000 \mathrm{~B}$ & 17.333 & $4.167 \mathrm{~A}$ \\
\hline Mg 4+Tuz & $1.837 \mathrm{~B}$ & $2.763 \mathrm{AB}$ & $6.353 \mathrm{~B}$ & $10.000 \mathrm{~B}$ & 17.867 & $5.000 \mathrm{~A}$ \\
\hline Mg 5+Tuz & $1.853 \mathrm{~B}$ & $2.287 \mathrm{~B}$ & $5.607 \mathrm{~B}$ & $9.66 \mathrm{~B}$ & 17.833 & $4.000 \mathrm{~A}$ \\
\hline
\end{tabular}

Aynı sütunda aynı büyük harfi alan ortalamalar arasındaki fark $\mathrm{P} \leq 0.05$ e göre önemsizdir.

\subsection{Yapraklardaki semptomlara göre skala değerleri}

Bitkilerde morfolojik olarak ortaya çıkan zararlanmanın derecesini ortaya koymak amacıyla yapılan skala oluşturma yönteminde belirtildiği şekilde fidelere 1 ile 5'e kadar puan verilmiştir. Skala değerlerine bakıldığında tuzdan en az etkilenen bitkilerin $\mathrm{Mg} 4+$ Tuz uygulamasında olduğu görülmektedir. Bunu sirasıyla Mg 3+Tuz, Mg 5+ Tuz ve Mg 2+Tuz uygulamaları izlemektedir. Morfolojik olarak en fazla zararlanma gören uygulama ise Mg 1+Tuz uygulamasıdır (Çizelge 3.)

Çizelge 3. Yapraklardaki semptomlara göre tuza dayanım skalası (puan)

\begin{tabular}{|c|c|}
\hline UYGULAMA & Skala değerleri \\
\hline Kontrol & 1 \\
\hline Mg 1+Tuz & 4.5 \\
\hline Mg 2+Tuz & 4 \\
\hline$M g$ 3+Tuz & 2.75 \\
\hline Mg 4+Tuz & 2.5 \\
\hline Mg 5+Tuz & 3 \\
\hline
\end{tabular}

\section{Tartışma ve Sonuç}

Araştırmada kullanılan Demre sivri biber çeşidine ait fideler Hoagland besin çözeltisi içinde yetiştirilmiş ve bu bitkilere tuz stresi uygulamak için $100 \mathrm{mM} \mathrm{NaCl}$ uygulanarak stres yaşatılmıştır. Bitkilere tuz uygulamasının yanında değişik dozlarda Mg uygulamaları yapılmış ve bitkilerin gelişme ve büyüme ile metabolik tepkiler yönünden karşılaştırması yapılmıştır. Tuz uygulamasının 20. gününde bitkilerin bazı gelişme parametrelerine bakılmış ve bu uygulamaların tuza dayanım skalaları 1-5 skalasına göre oluşturulmuştur. Tuz uygulaması ile birlikte artan dozlarda Mg uygulanan biber bitkilerinin büyüme ve gelişme parametrelerinden kök, gövde ve yaprak ağırlı̆̆ bakımından ufak da olsa artışlar gözlemlenmiştir. Tuz uygulamaları içinden en yüksek kök, gövde ve yaprak ağırlığı $\mathrm{Mg}$ 'un dördüncü dozundan alınmıştır. Aynı durumlar yaprak sayısı, bitki boyu ve boğum arası bakımından da gözlemlenmiştir. $\mathrm{NaCl}$, su potansiyelini azaltmakta ve hücredeki iyon dengesini bozarak da bitki gelişimini olumsuz etkilemektedir. Irshad vd. (2002) tarafindan yürütülen çalışmalar sonucunda tuz stresi altındaki bitkilerde köklerin su alma yeteneklerinde önemli azalmalar meydana geldiğinden, kök gelişimi 
ve gövde uzamasında gerilemenin olduğu bildirilmiştir. Stres altındaki bitkilerin gövde çaplarnın azaldığ1 gibi boylarınında kontrole göre küçük kaldığı, aynı şekilde yaprak alanı ve generatif evreye geçişte çiçeklenme ve meyve veriminin de olumsuz etkilediği bildirilmiştir. Benzer şekilde Akdoğan ve Özkan (2000), fide dikimi, çiçeklenme ve meyve oluşumu dönemlerinde uygulanan su stresinin artan tuzluluk değerlerinde, kök ve gövde kuru madde miktarı ve ürün miktarında azalmaya neden olduğunu bildirmiştir. Benzer şekilde Munns ve Termaat (1986), Snap ve Shennan (1992), Romero-Aranda ve ark. (2001), Karanlık (2001), Çiçek ve Çakırlar (2002), Yaşar (2003), Lacerda ve ark. (2005), Cavalcanti ve ark. (2007), Üzal (2009) ve Öztaş (2018) gibi araştırıcılar tuz stresi altındaki bitkilerin gelişiminin olumsuz şekilde etkilendiğini rapor etmişlerdir. Tuz stresinin bitki gelişimi üzerine olumsuz etkisini azaltabileceği öngörüsüyle yaptığımız bu çalışmada tuz stresi altındaki bitkilerin gelişimi üzerine Mg'un artan dozlarının olumlu etkisinin olduğu yapılan ölçüm ve gözlemler sonucunda söylenebilir.

\section{Kaynaklar}

Akdoğan, S., Özkan, İ., (2000).Gelişmenin değişik dönemlerinde uygulanan su noksanlığ1 geriliminin biber bitkisi (Capsicum annuum L.)'nin tuza duyarlılı̆̆ı üzerine etkisi, AÜ Ziraat Fakültesi Dergisi, 6(3): 1-8

Asraf, M. (2004) Some important physiological selection criteria for salt tolerance in plants, Flora, 199:361-376

Bartels, D. ve Sunkar, R. (2005) Drought and salt tolerance in plants, Critical Reviews in Plant Sciences, 24: 23-58

Cavalcanti, F. R. ve ark. (2007) Roots and leaves display contrasting oxidative response during salt stress and recovery in cowpea. Journal of plant physiology, 164(5): 591-600

Çiçek, N., Çakırlar, H. (2002) The effect of salinity on some physiological parameters in two maize cultivars, Bulg. J. Plant Physiol., 28 (1-2): 66-74

Hoagland, D.R., Arnon, D.I. (1938) The water culture method for growing plants without soil. California Agricultural Experiment Station Circulation,347, 32

Irshad, M. ve ark. (2002) Urea and Manure Effect on Growth and Mineral Contents fof Maize Under Saline Conditions. J Plant Nutrit, 25(1): 189- 200

Karanlık, S. (2001) Değişik Buğday Genotiplerinde Tuz Stresine Dayanıklılık ve Dayanıklılı̆̆ın Fizyolojik Nedenlerinin Araştırılması.(doktora tezi, basılmamış). Çukurova Üniversitesi Fen Bilimleri Enstitüsü Adana

Lacerda, C. F. ve ark. (2005) Changes in growth and in solute concentrations in sorghum leaves and roots during salt stress recovery. Environmental and Experimental Botany, 54(1): 69-76

Mahajan, S., Pveey, G. K. \&Tuteja, N. (2008) Calcium- and salt-stress signaling in plants: shedding light on SOS pathway, Archives of Biochemistry and Biophysics, 471(2): 146-158

Munns, R. ve Termaat, A. (1986) Whole-plant responses to salinity. Aust. Journal Plant Physiology., $13 ; 143-160$

Oztekin GB, Tuzel Y (2011) Salinity response of some tomato rootstocks at seedling stage. African Journal of Agricultural Research, 6(20): 4726-4735

Öztaş, Ö. (2018) Tuz Stresi Altındaki Biber Bitkisine Potasyum Uygulamalarının Etkisinin Araştırılması. Yüzüncü Yıl Üniversitesi, Fen Bilimleri Enstitüsü, Van. 
Romero-Aranda, R., T. Soria \& J. Cuartero. (2001) Tomato plant-water uptake and plantwater relationships under saline growth conditions. Plant Sci., 160:265- 272.

Sas-Institue, (1985) Sas/State User's Guide 6. 03 ed. SAS. Institute. Cary,North Carolina.

Snapp, S.S., Shennan C., (1992). Effects of Salinity of Root and Deth Dynamics of Tomato, Lycopersicum esculentum Mill., New Phytologist.,121: 71-79.

Taiz, L., Zeiger, E. (2002). Plant Physiology, Sunderland, MA, Sinauer Associates, Inc.

Üzal, Ö. (2009). Tuz Stresi Altında Yetişstirilen Bazı Çilek Çeşitlerinde Jasmonik Asitin Bitki Gelişimi ve Antioksidant Enzim Aktiviteleri Üzerine Etkisi. (Doktora Tezi). Yüzüncü Yıl Üniversitesi. Fen Bilimleri Enstitüsü, Van.

Yaşar, F. (2003) Tuz Stresi Altındaki Patlıcan Genotiplerinde Bazı Antioksidant Enzim Aktivitelerinin in vitro ve in vivo Olarak İncelenmesi. (doktora tezi basılmamış). Yüzüncü Yıl Üniversitesi, Fen Bil. Enst, Van.

Yu S., Wang W. \& Wang B. (2012) Recent progress of salinity tolerance research in plants, Russian Journal of Genetics, 48 (5): 497-505. 